HELMINTHOLOGIA, 54, 4: 348 - 357, 2017

\title{
Spermiogenesis and sperm ultrastructure in Calicotyle affinis Scott, 1911 (Platyhelminthes, Monogenea, Monopisthocotylea, Monocotylidae)
}

\author{
M. BRUŇANSKÁ' ${ }^{1 *}$, L. G. PODDUBNAYA ${ }^{2}$
}

${ }^{1 *}$ Institute of Parasitology, Slovak Academy of Sciences, Hlinkova 3, 04001 Košice, Slovak Republic, E-mail: brunan@saske.sk; 2I.D. Papanin Institute for Biology of Inland Waters, Russian Academy of Sciences, 152742 Borok, Yaroslavl Province, Russia

\section{Article info}

Received June 29, 2017 Accepted August 8, 2017

\begin{abstract}
Summary
Spermatological characteristics of Calicotyle affinis Scott, 1911, an endoparasitic monocotylid monogenean from the cloaca of a holocephalan fish Chimaera monstrosa $\mathrm{L}$, have been investigated by means of transmission electron microscopy for the first time. Spermiogenesis exhibits features basically similar to those of the congeneric Calicotyle kroyeri and Calicotyle australiensis, but there are some new findings with respect to the formation and fine structure of the spermatozoon including the remarkable complex end-piece (EP). Morphogenesis of the EP, which is located at the anterior (proximal) region of the late spermatid, includes two stages: (1) the centriolar region is continuous with a cytoplasmic mass of the zone of differentiation, the electron-dense surface of the spermatid undergoes significant changes in the sculpturing and the inner core of developing spermatid is electron-lucent; (2) after central fusion of the arching membranes a definitive structure of the EP is subsequently evolved, finally comprising $3-4$ electron-dense discs attached to a central common electron-lucent column. The EP is considered as a synapomorphy of the genera Calicotyle + Dictyocotyle. The mature spermatozoon of $C$. affinis comprises the EP, two parallel axonemes of almost equal lengths with the $9+$ " 1 " trepaxonematan pattern, mitochondrion, nucleus, and a reduced number of parallel cortical microtubules $(1-3)$. The posterior (distal) extremity of the mature spematozoon contains a single tapering axoneme. Ultrastructural characteristics of the mature spermatozoon of C. affinis coincide mostly with those of congeneric $C$. australiensis. Variations of the spermatological characters within the genus Calicotyle, between Calicotyle and enigmatic Dictyocotyle as well as other monocotylid monogeneans are discussed.
\end{abstract}

Keywords: Calicotyle affinis; Monogenea; ultrastructure; spermiogenesis

\section{Introduction}

The monocotylid genus Calicotyle Diesing, 1850 comprises 14 valid species, parasites of elasmobranchs and holocephalans (Chisholm et al., 1997). Calicotyle is a somewhat unusual monogenean in that it is endoparasitic, found in the cloaca, rectum, rectal gland, spiral valve, or oviducts of its hosts (Sproston, 1946; Yamaguti, 1963; Chisholm et al., 1995, 2001). In the past, this pa- rasite has attracted attention of numerous investigators and various aspects of biology of Calicotyle were studied using molecular and morphological methods, including electron microscopy. Ultrastructural sperm characters are of special phylogenetic importance in the Platyhelminthes (Justine et al., 1985; Rohde, 1988; Justine, 1991a, b, 1993, 1998, 2001; Hoberg et al., 2001; Bruňanská, 2010; Levron et al., 2010; Kearn \& Whittington, 2015). Even at the genus level, sperm characteristics may contribute to

\footnotetext{
$\overline{* \text { - corresponding author }}$
} 

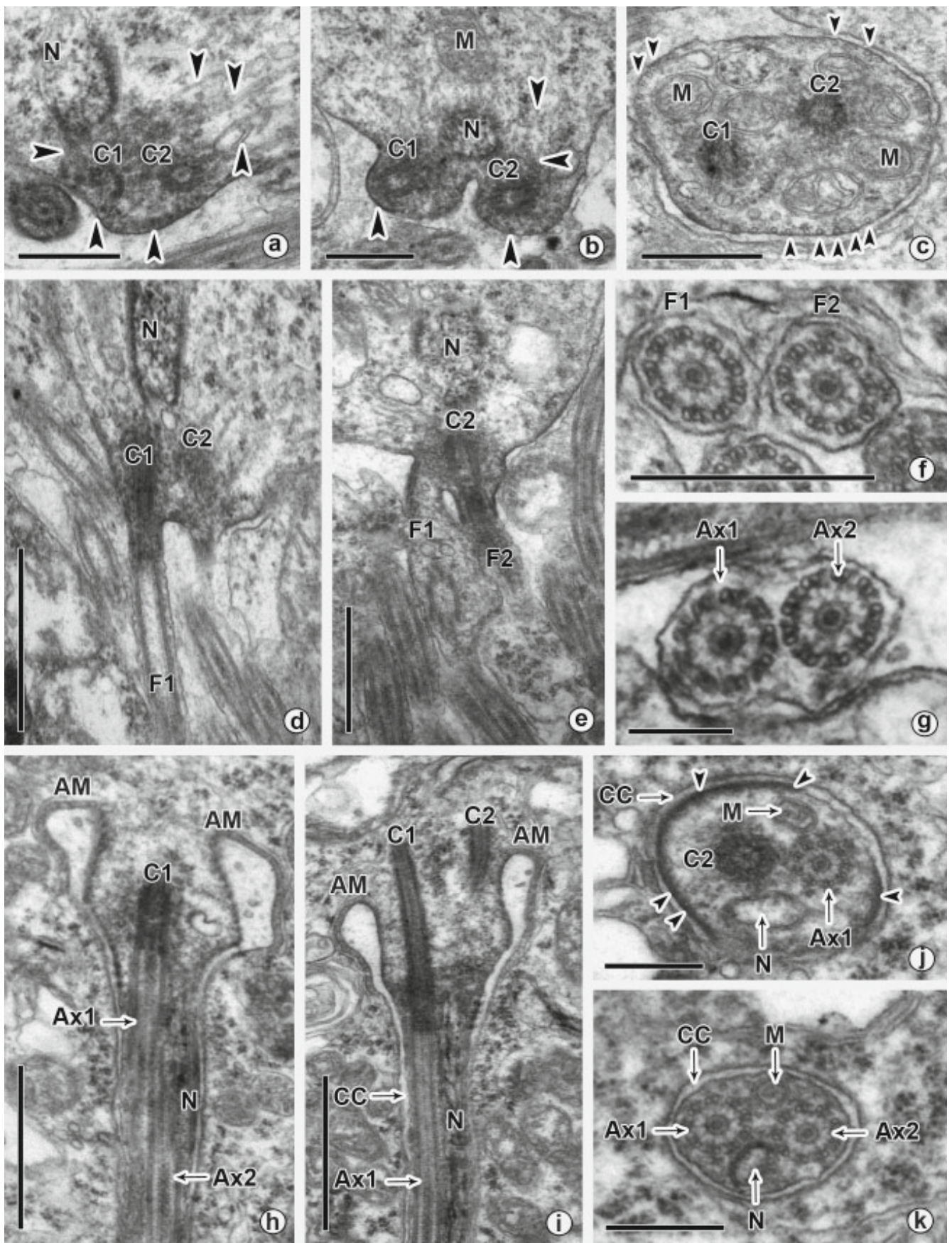

Fig. 1. (a - k) Early and advanced stages of spermiogenesis in Calicotyle affinis.

(a) The two parallel centrioles $(\mathrm{C} 1, \mathrm{C} 2)$ in the apical region of the zone of differentiation. arrowheads - microtubules, $\mathrm{N}$ - nucleus of the early spermatid. Scale bar $=0.5 \mu \mathrm{m}$. (b) Each of the two centrioles $(\mathrm{C} 1, \mathrm{C} 2)$ is often situated in a small separated protuberances. $\mathrm{M}$ - mitochondrion, $\mathrm{N}-$ nucleus. Scale bar $=0.5 \mu \mathrm{m}$. (c)

Cross-section through the base of the zone of differentiation. arrowheads - cortical microtubules, $\mathrm{C} 1, \mathrm{C} 2-$ centrioles, $\mathrm{M}$ - mitochondrion. Scale bar $=0.5 \mu \mathrm{m}$.

(d) Two parallel flagella (F1, F2 not shown) extend from the two centrioles (C1, C2) in the zone of differentiation. $N$ - nucleus. Scale bar $=1 \mu \mathrm{m}$. (e) The fusion of two free flagella (F1, F2) resulting into their incorporation in the cytoplasm of the zone of differentiation. C2 - centriole, $\mathrm{N}$ - nucleus. Scale bar $=1 \mu \mathrm{m}$. (f) Cross-section through the two free flagella $(F 1, F 2)$ before their fusion in advanced stages of spermiogenesis. Scale bar $=0.5 \mu \mathrm{m}$. (g) Cross-section through the two axonemes $(\mathrm{Ax} 1, \mathrm{Ax2})$ after fusion of two free flagella (seen in Fig. 1f) in advanced stages of spermiogenesis. Scale bar $=0.2 \mu \mathrm{m}$. (h) Longitudinal section through the spermatid during migration of the nucleus (N). AM - arching membranes, Ax1, Ax2 - axonemes, $C 1$ - centriole. Scale bar $=1 \mu \mathrm{m}$. (i) Longitudinal section of late spermatid during formation of a cytoplasmic canal (CC). AM - arching membranes, Ax1 - axoneme, C1, C2 - centrioles, $\mathrm{N}$ - nucleus. Scale bar $=1 \mu \mathrm{m}$. (j) ) Cross-section through the base of the late spermatid. arrowhead - cortical microtubules, Ax1 - axoneme, C2 - centriole, CC - cytoplasmic canal, M - mitochondrion. Scale bar $=0.3 \mu \mathrm{m}$. (k) Cross-section through the main body of the late spermatid. Ax1, Ax2 - axonemes, $C C$ - cytoplasmic canal, $\mathrm{M}$ - mitochondrion, $\mathrm{N}$ - nucleus. Scale bar $=0.3 \mu \mathrm{m}$. 
resolving relationships (Watson \& Chisholm, 1998). Within the Monocotylidae, spermiogenesis and spermatozoon ultrastructure of 9 species from 5 of the 6 subfamilies identified by Chisholm et al. (1995) were studied (see Bruňanská et al., 2017). These data include two species of the genus Calicotyle, namely Calicotyle kroyeri and Calicotyle australiensis (Tappenden \& Kern, 1991; Watson \& Rohde, 1994). Interestingly, some differences were found between spermatological features of the two latter species, particularly with respect to the formation and ultrastructure of the proximal end-piece (EP) which develops late in spermiogenesis, and ultrastructure of the mature spermatozoon. In addition, there are still questions concerning the presence/absence of the EP in the mature spermatozoa from reproductive ducts in the genus Calicotyle.

Therefore, the present study of C. affinis Scott, 1911 was undertaken in order (a) to determine whether any further variation exists in the ultrastructural characteristics of sperm/spermiogenesis of the genus Calicotyle, and (b) to provide additional data for comparative, systematic and phylogenetic analyses.

\section{Materials and Methods}

Specimens of Calicotyle affinis were recovered from the cloaca of naturally infected holocephalan fish, Chimaera monstrosa Linnaeus, 1758 caught in the Norwegian Sea off Tromsø, Norway. Live specimens were fixed using $4 \%$ glutaraldehyde in $0.1 \mathrm{M}$ sodium phosphate buffer ( $\mathrm{pH} 7.4$ ) for 20 days, postfixed in $1 \% \mathrm{OsO}_{4}$ and then dehydrated in a graded ethanol series, with a final change to absolute ethanol. For transmission electron microscopy, specimens were embedded in a mixture of Araldite and Epon. Ultrathin sections (70 - $90 \mathrm{~nm}$ in thickness) were stained with uranyl acetate and lead citrate, and then examined using a JEOL JEM 1011 transmission electron microscope operating at $80 \mathrm{kV}$.

\section{Results}

\section{Spermiogenesis}

The testicular follicles of Calicotyle affinis occupy the intercaecal region posterior to ovary. They contain male gametes at various developmental stages, including spermatids.

The first sign of ongoing spermiogenesis is the formation of a differentiation zone (ZD) situated at the periphery of each spermatid (Figs. 1a, 3a). This is a conical protrusion containing the two centrioles (without rootlets) orientated parallel to the long axis of the nucleus. Occasionally, each centriole may be situated in a separated protuberance (Fig. 1b). The two centrioles are interconnected with microtubules (Figs. 1a, b). The ZD is lined with cortical microtubules (CMs) arranged under the cell membrane of the spermatid (Figs 1a, b, c).

The two free flagella grow outwards and do not exhibit a central core in the early stages of spermiogenesis (Figs. 1d, e). Well-developed free flagella have typical $9+$ "1" structure (Figs. 1f, 3b) and soon fuse with each other (Figs. 1g, 3c). After flagellar fusion, the arching membrane lines the proximal extremity of the ZD (Figs. 1h, i). It consists of a double membrane located beneath the cell membrane of the spermatid. Longitudinal and cross-sections reveal penetration of the mitochondrion and the nucleus into the ZD at this stage of spermiogenesis (Figs. 1h, i, j, k). A parallel cytoplasmic canal separates the ZD from the common cytoplasmic mass. The CMs are arranged in a complete ring under the plasma membrane in the most proximal part of the ZD (Figs. 1j, 3d). More distally, the CMs disappear (Fig. 1k).

A complex end-piece (EP) is formed at the anterior extremity of the late spermatid. Morphogenesis of the EP includes two stages (Figs. 2a, b, c, d). Firstly, the developing EP is continuous with a cytoplasmic mass of the ZD and characterised by significant thickening and changes in the sculpturing of the surface of the spermatid (Fig. 2a, 3e). The inner core of the spermatid is less electron-dense. After central fusion of the arching membranes, the spermatid becomes separated and its anterior extremity shows a spiral pattern arrangement exhibiting 3 turns (Figs. 2b). The EP surface displays the dense outer layer. The following stage in the differentiation of the EP is characterised by condensation of the inner less electron-dense core, thus resulting in a complex endpiece composed of $3-4$ electron-dense discs attached to a central common electron-lucent column (Figs. 2c, d, 3f). A base of the EP is tightly associated with the proximal extremity of the late spermatid. Two pairs of tiny protuberances are visible in longitudinal sections of the EP base (Figs. 2c, d).

Cross sections reveal the presence of the nucleus in the anterior (proximal) (Fig. 2e), middle (Figs. 2f, g, h) and posterior (distal) (Fig. 2i) regions of the late spermatid. A greatly reduced number of CMs $(1-2)$ was detected along the periphery of the spermatid, in the vicinity of the nucleus in the anterior third of the cell (Fig. 2f). Occasionally, CMs are arranged between the nucleus and the axoneme (Fig. $2 \mathrm{~g}$ ). In the more distal region of the late spermatid the CMs disappear (Figs. 2h, i).

\section{Mature Spermatozoon}

Numerous longitudinal and cross sections through sperm ducts of C. affinis revealed that the mature spermatozoon is a filiform cell. It contains the EP, two parallel axonemes of almost equal lengths exhibiting the $9+$ " 1 " pattern of the Trepaxonemata, parallel CMs, a mitochondrion, and a nucleus. Five distinct regions $(\mathrm{I}-\mathrm{V})$ of the spermatozoon show characteristic ultrastructural features.

Region I (Figs. 4a, b and 5I) constitutes the anterior (proximal) part of the spermatozoon. The most characteristic feature of this region is the proximal EP which exhibits $3-4$ turns and is made of electron-dense, coarsely granular material (Fig. 4a). Two small electron-dense protuberances are localised at the base of the EP in longitudinal (Fig. 4a, I) and transverse (Fig. 4b) sections. Small profiles of the mitochondrion and nucleus are present.

Region II (Figs. 4c, d, e and 5II) ) is characterized by the presence of two axonemes, a mitochondrion exhibiting irregularly enlarged 

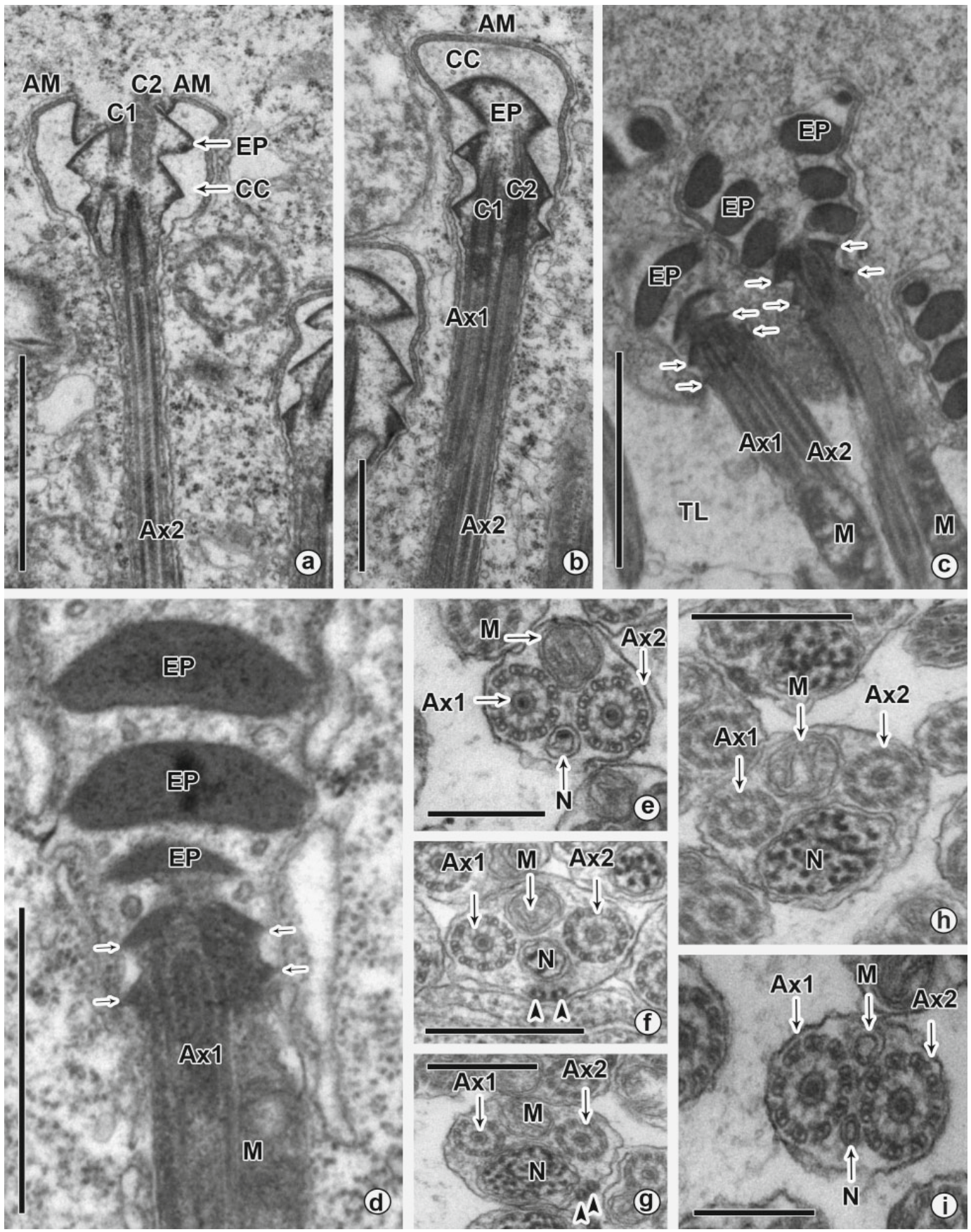

Fig. 2. (a-i) Advanced and final stages of spermiogenesis in $C$ affinis.

(a) Longitudinal section of a late spermatid at initial stage of the formation of the end-piece (EP). AM - arching membranes, Ax2 - axoneme, CC - cytoplasmic canal, $\mathrm{C} 1, \mathrm{C} 2$ - centrioles. Scale bar $=2 \mu \mathrm{m}$. (b) Longitudinal section of a late spermatid at more advanced stage of the formation of the end-piece (EP). Note the central fusion of arching membranes (AM) is complete. Ax1, Ax2 - axonemes, CC - cytoplasmic canal, C1, C2 - centrioles. Scale bar $=1 \mu \mathrm{m}$. (c) Before the end of spermiogenesis, fully formed end-pieces (EP) are still embedded in a cytoplasmic mass whereas the main bodies of late spermatids occupy the testis lumen (TL). Ax1, Ax2 - axonemes, $M$ - mitochondrion, small arrows - tiny protuberances at the base of the end-piece.. Scale bar $=2 \mu \mathrm{m}$. (d) A detail of the fully formed end-pieces (EP) interface of a late spermatid. Ax1 - axoneme, M - mitochondrion, small arrow - protuberances of the base of EP. Scale bar $=1 \mu \mathrm{m}$. (e) Cross-section through the anterior part (below the end-piece) of the late spermatid. Ax1, Ax2 - axonemes, $M$ - mitochondrion, $N$ - nucleus. Scale bar $=0.25 \mu \mathrm{m}$. (f) Cross-section through the late spermatid reveals enlarged profile of nucleus $(\mathrm{N})$ and one pair of cortical microtubules (arrowhead). $A \times 1, A \times 2-$ axonemes, $M-$ mitochondrion. Scale bar $=0.5 \mu \mathrm{m}$. (g) Cortical microtubules (arrowheads) are occasionally situated between nucleus ( $\mathrm{N}$ ) and axoneme (Ax2). Ax1-axoneme, $\mathrm{M}$ - mitochondrion. Scale bar $=0.5 \mu \mathrm{m}$. (h) Cross-section through the late spermatid shows large profile of the nucleus (N). Note the absence of cortical microtubules. Ax1, Ax2 - axonemes, $\mathrm{M}$ - mitochondrion. Scale bar $=0.5 \mu \mathrm{m}$. (i) Cross-section through the posterior part of the late spermatid. Ax1, Ax2 - axonemes, $\mathrm{M}$ - mitochondrion, $\mathrm{N}$ - nucleus. Scale bar $=0.25 \mu \mathrm{m}$. 
a
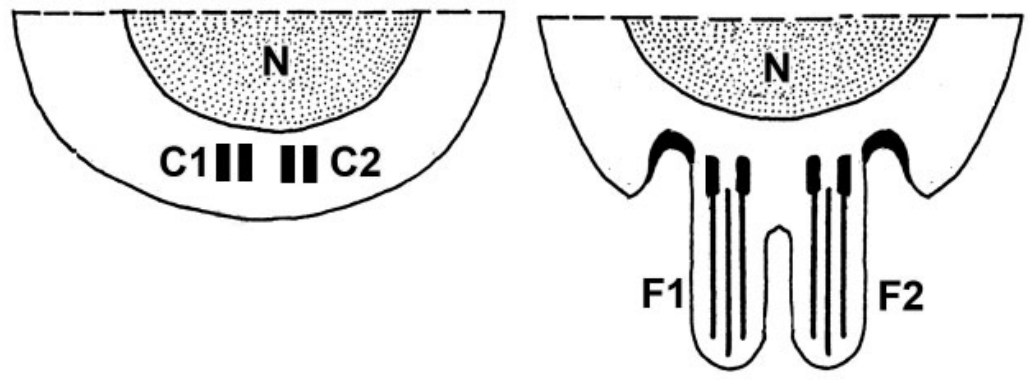

d

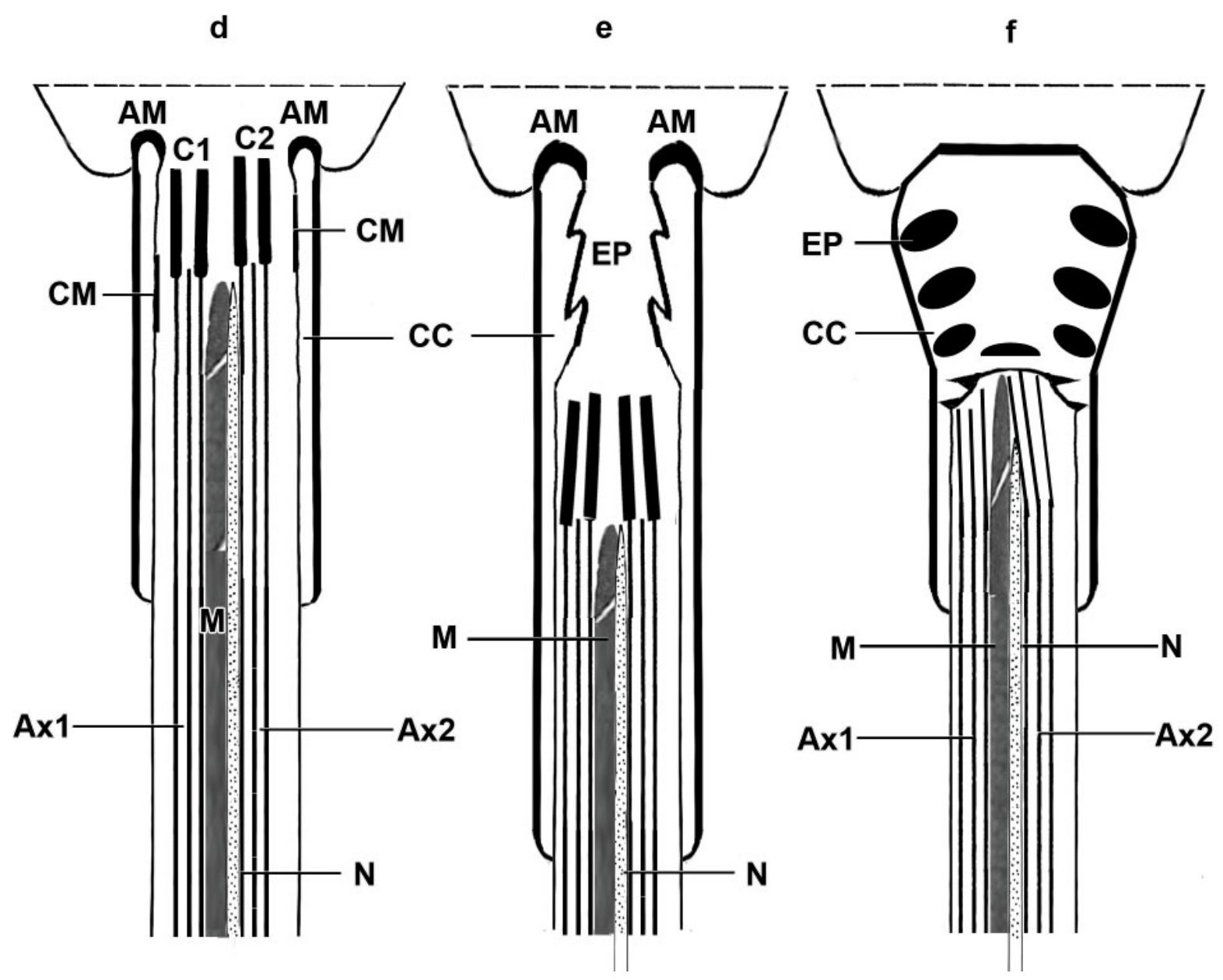

b

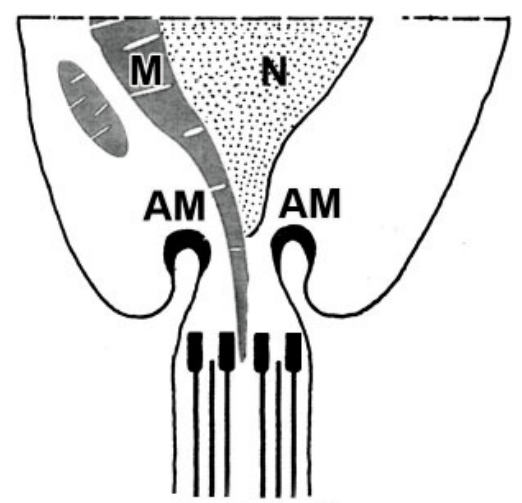

Ax1 Ax2

Fig. 3. Schematic reconstruction of the main stages of spermiogenesis in $C$. affinis.

( $a$, b: the early stages; c, d, e: the advanced stage; f: the final stage). AM - arching membranes, Ax1, Ax2 - axonemes, C1, C2 - centrioles, CC - cytoplasmic canal, $\mathrm{CM}$ - cortical microtubules, EP - end-piece, F1, F2 - flagella, M- mitochondrion, $\mathrm{N}$ - nucleus. 
portions, a small profile of nucleus and three CMs situated underneath the nucleus.

Region III (Figs. 4f, g, h, i and 5III) is the middle part of the spermatozoon, with the two axonemes, mitochondrion, and an enlarged profile of the nucleus. In cross sections, the nucleus is oval to circular in shape. Accidental and rare fusion of two spermatozoa was detected occasionally in sperm ducts (Fig. 4h). More distally, the diameters of the cell, the mitochondrion, and the nucleus gradually diminish (Fig. 4i).

Region IV (Fig. 4j and 5IV) is the posterior (distal) region with two axonemes and very reduced profiles of the mitochondrion and nucleus.

Region V (Figs. 4k, I and 5V) is the posterior extremity of the spermatozoon. The single axoneme (Figs. 4k, j) is disorganised in this region.

\section{Discussion}

Results of the present study provide a set of spermatology information, which shows that the process of spermiogenesis in Calicotyle affinis exhibits basic features described previously for related members of the monocotylid subfamily Calicotylinae (see Bruňanská et al., 2017); but there are also some remarkable differences. The shared pattern includes e.g. a complete ring of microtubules in the zone of differentiation (ZD), fusion of 2 initially free flagella, absence of a median cytoplasmic process, intercentriolar body and flagellar rootlets in the ZD, migration of the nucleus and mitochondrion alongside the now-incorporated axonemes, and development of spermatids in parallel cytoplasmic canals formed in the main cytoplasmic mass. It is worth noting that a complete ring of microtubules in the $\mathrm{ZD}$ has been observed exclusively in the Calicotylinae by various authors (Tappenden \& Kern, 1991; Watson \& Rohde, 1994; Bruňanská et al., 2017; present study) whereas in other monocotylid subfamilies, an incomplete ring of microtubules or a few microtubules are present in the ZD (see Watson \& Rohde, 1994). In contrast to C. affinis (present study) and Dictyocotyle coeliaca (Bruňanská et al., 2017) which exhibit no density/external ornamentation associated with the microtubules in the ZD, the cortical microtubules of most monocotylids are associated with externally situated dense material and adjacent external ornamentation of the plasma membrane in the ZD.

Some further differences were noted with regard to the position of centrioles in early spermiogenesis of the members of the Calicotylinae. The two centrioles are orientated either at right angles to each other e.g. in C. australiensis (Watson \& Rohde, 1994) and D. coeliaca (Bruňanská et al., 2017), or they are situated parallel to the long axis of the nucleus in C. affinis (present study) and $C$. kroyeri (Tappenden \& Kern, 1991). The centrioles give rise to the two free flagella, which fuse with each other (C. affinis, C. kroyeri) or rotate to lie parallel before fusion $(C$. australiensis, $D$. coeliaca). In contrast, the dionchids and capsalids (Monopisthocotylea) exhibit parallel centrioles which produce the two axonemes being enclosed from their inception in the same body of cytoplasm (Justine \& Mattei, 1983a, 1987).

The complex end-piece (EP) of spermatids of $C$. affinis is a remarkable feature which has been reported previously only during spermiogenesis of the genus Calicotyle (Tappenden \& Kern, 1991; Watson \& Rohde, 1994, present study). The developing EP of $C$. affinis at the end of the first developmental stage (present study) resembles the EP of the late spermatid in $D$. coeliaca (Bruňanská et al., 2017). Thus, the fully developed electron-dense EP is characteristic exclusively of Calicotyle. However, the presence of developing EP in the late spermatid of $D$. coeliaca suggests that this structure should be considered as a synapomorphy of the genera Calicotyle + Dictyocotyle. By comparison, the EP exhibits $3-4$ turns in C. australiensis (Watson \& Rohde, 1994), 3 - 4 turns in C. affinis (present study) and $7-8$ turns in $C$. kroyeri (Tappenden \& Kern, 1991). The EP was found associated with spermatozoa lying free in the testis lumen of all three species of Calicotyle studied to date. However, it is retained only in the mature spermatozoa of $C$. affinis (present study) and C. australiensis (Watson \& Rohde, 1994), and is absent in mature male gametes from the vas deferens, seminal receptacle, or vagina in C. kroyeri (Tappenden \& Kern, 1991). On the other hand, the EP remains in the residual cytoplasm even at the end of spermiogenesis of $D$. coeliaca (Bruňanská et al., 2017). The EP situated at the extremity proximal to the axonemes in the Calicotylinae is in sharp contrast with a single dense crest described as a short helix around the sperm body (not terminal) in the monogenean Calceostoma herculanea (Calceostomatidae) (Justine \& Mattei, 1986). The latter may resemble more closely crested bodies (CB) of some Eucestoda e.g. some Bothriocephalidea, Tetraphyllidea - Onchobothriidae, Tetraphyllidea - Phyllobothriidae, Proteocephalidea, Nippotaeniidea or Cyclophyllidea (Bruňanská, 2010; Levron et al., 2010; Bruňanská et al., 2015). However, the CB are terminal structures localised under the plasma membrane and coiled in a spiral on the periphery and around the axoneme(s) of the spermatozoa in cestodes. In addition, the EP of monogeneans is present exclusively in the basal group of the Monocotylidae (Calicotylinae) whereas the CB of the Eucestoda is detected in more derived groups only, never in the presumably basal groups (Caryophyllidea, Spathebothriidea, Diphyllobothriidea) (Bruňanská, 2010; Levron et al., 2010). The role and chemical composition of the EP, dense crest, or CB remain still unknown.

The basic cellular components of the mature spermatozoon of C. affinis resemble those of other members of the Calicotylinae in having two axonemes of almost equal lengths with a $9+$ "1" trepaxonematan pattern (Ehlers 1985), a single mitochondrion, nucleus, and two parallel cortical microtubules. By comparison, the mature spermatozoa of $C$. kroyeri exhibit regions with a single axonemal profile resulting from a shift of the two axonemes described also in monocotylid species from subfamilies Heterocotylinae, Merizocotylinae, or Dasybatotreminae (Watson, 1997) or some species of the Monopisthocotylea (Watson \& Rohde, 1994). 

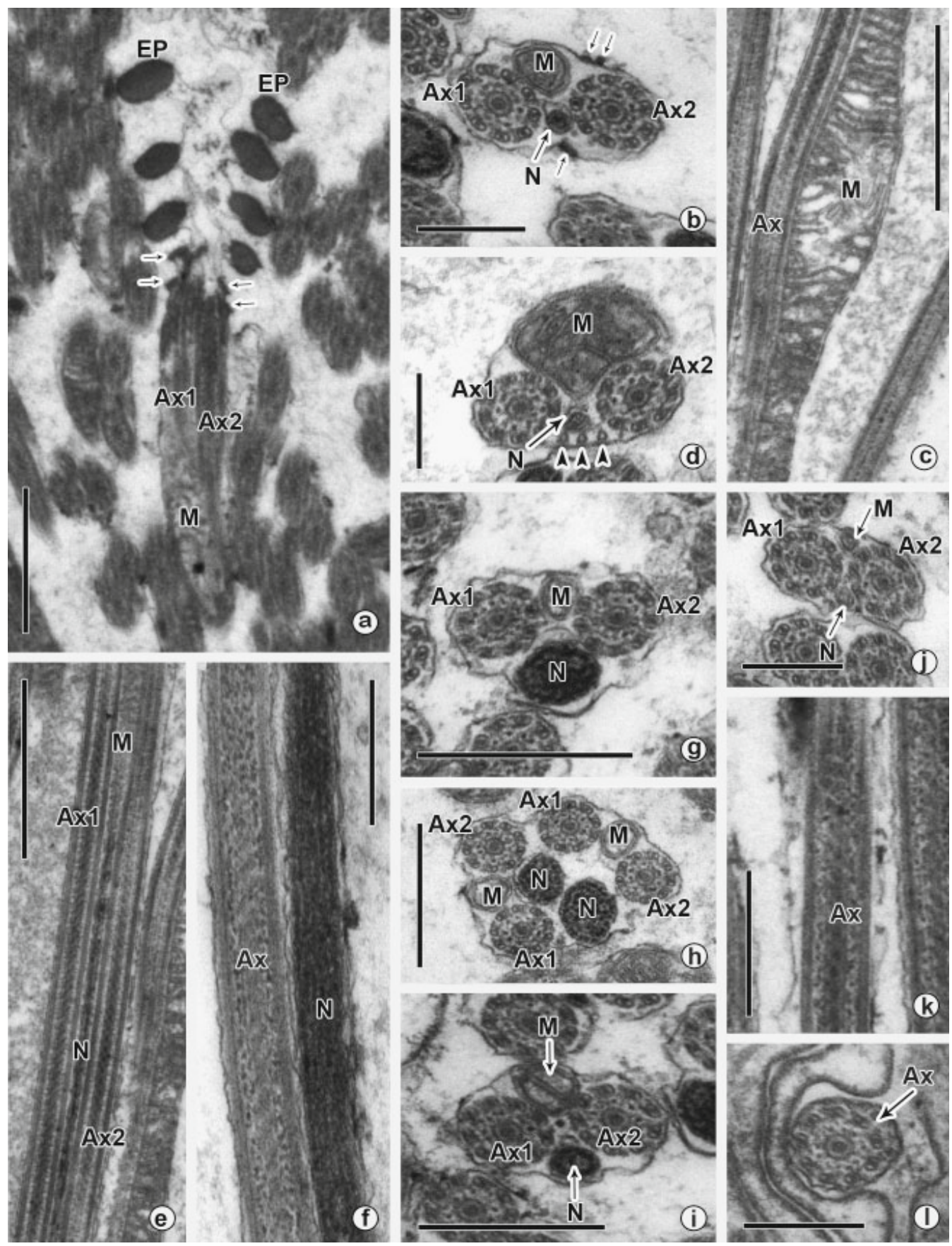

Fig. 4. (a - I) Ultrastructure of the spermatozoon of $C$. affinis.

(a) Longitudinal section of the spermatozoon (region I) from vas deferens. Ax1, Ax2 - axonemes, EP - end-piece, $\mathrm{M}$ - mitochondrion, small arrows - tiny protuberances at the base of EP. Scale bar $=1 \mu \mathrm{m}$. (b) Cross-section of the anterior extremity of the spermatozoon. Ax1, Ax2 - axonemes, $\mathrm{M}$ - mitochondrion, $\mathrm{N}$ - nucleus, small arrows - tiny protuberances at the base of the end-piece. Scale bar $=0.25 \mu \mathrm{m}$. (c) Longitudinal section of the region II with slightly increased profile of a mitochondrion (M). $\mathrm{Ax}$ - axoneme. Scale bar $=1 \mu \mathrm{m}$. (d) Cross-section of the region II with slightly increased profile of a mitochondrion (M). arrowheads - cortical microtubules, Ax1,

Ax2 - axonemes, $\mathrm{M}$ - mitochondrion, $\mathrm{N}$ - nucleus. Scale bar $=0.25 \mu \mathrm{m}$. (e) ) Longitudinal section of the region II with standard profile of a mitochondrion $(\mathrm{M})$ and small profile of a nucleus (N). Ax1, Ax2 - axonemes. Scale bar $=1 \mu \mathrm{m}$. (f) Longitudinal section of the region III with an enlarged profile of a nucleus $(\mathrm{N})$. Ax - axoneme. Scale bar $=0.25 \mu \mathrm{m}$. (g) Cross section through the middle part of the region III of the spematozoon with the nucleus (N), two incorporated axonemes (Ax1, Ax2) and a mitochondrion $(M)$. Scale bar $=0.5 \mu \mathrm{m}$. (h) Atypical spermatozoa with four incorporated axonemes ( $A \times 1, A \times 2)$ from the vas deferens. $M-$ mitochondrion, $N-$ nucleus. Scale bar $=0.5 \mu \mathrm{m}$. (i) Cross sections of the distal part of the region III of the spermatozoon. Ax1, Ax2 - axonemes, $\mathrm{M}-$ mitochondrion, $\mathrm{N}-$ nucleus. Scale bar $=0.5 \mu \mathrm{m}$. (j) Cross sections of the region IV of the spermatozoon. Ax1, Ax2 - axonemes, M - mitochondrion, N- nucleus. Scale bar $=0.25 \mu \mathrm{m}$. (k) Longitudinal section of the region V. Ax - axoneme. Scale bar $=0.5 \mu \mathrm{m}$. (I) Cross sections of the region $\mathrm{V}$ of the spermatozoon. $A x-$ axoneme. Scale bar $=0.25 \mu \mathrm{m}$. 
(1)

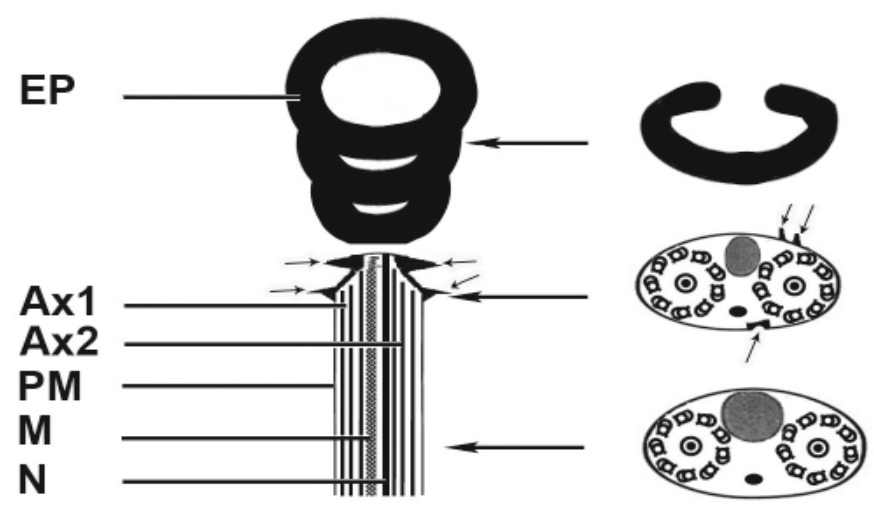

(II)
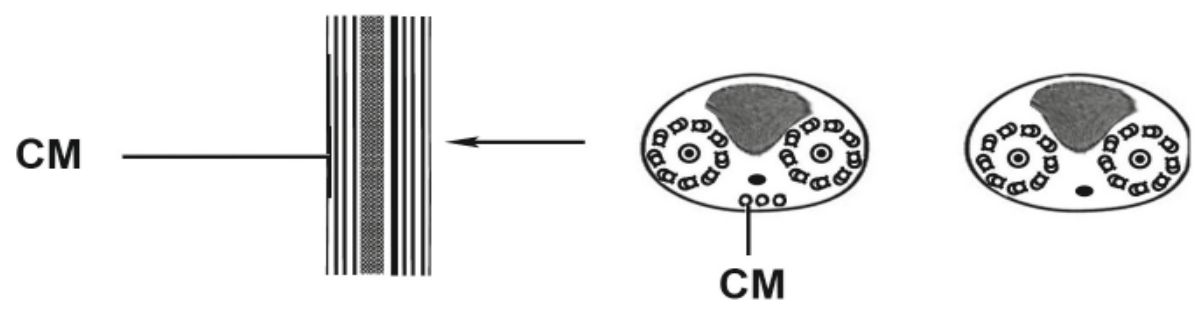

(III)
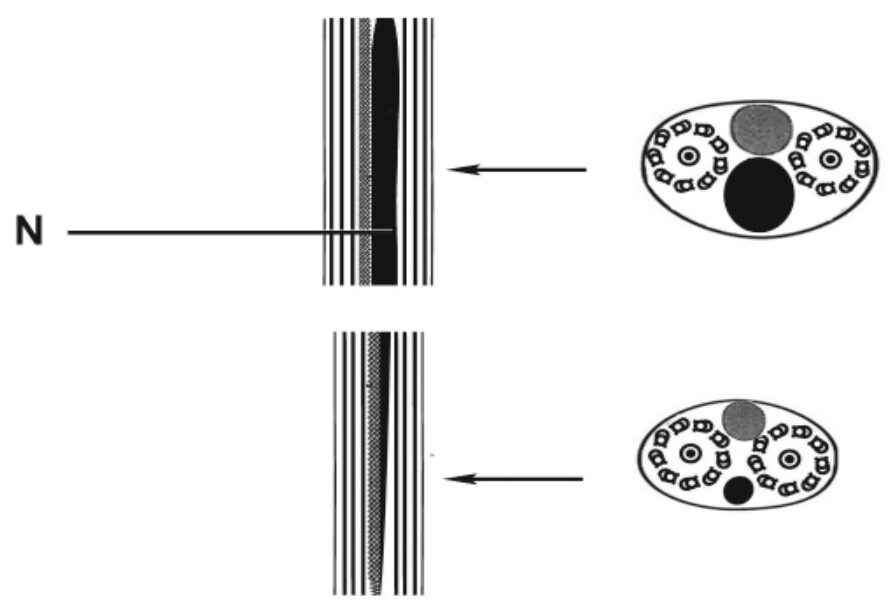

(IV)
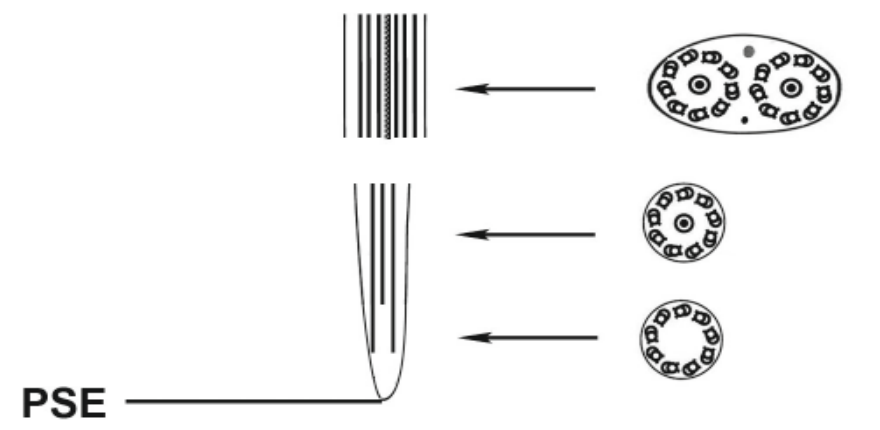

(v)

Fig. 5. Schematic reconstruction of the mature spermatozoon of $C$. affinis.

Ax1, 2 - axonemes, CM - cortical microtubules, EP - end-piece, $\mathrm{M}$ - mitochondrion, $\mathrm{N}$ - nucleus, PM - plasma membrane, PSE - posterior spermatozoon extremity, small arrows - tiny protuberances at the base of the EP. 
Nevertheless, the presence of the two axonemes of almost equal lengths in Calicotyle spp. and $D$. coeliaca might be interpreted as the basal situation in the Monocotylidae. The two axonemes of unequal lengths e.g. in Heterocotyle sp. (Justine and Mattei 1983b) represent a more derived characters within Monocotylidae. The character pattern of the nucleus of mature spermatozoa shows some differences.

The nucleus is considered to occupy a posterior position in the spermatozoa of the monopisthocotylean Monogenea (Justine \& Mattei, 1983c, 1984) and all Neodermata (Justine, 2001; Bruňanská, 2010; Levron et al., 2010). A few profiles of nucleus were detected in the distal spermatozoon extremity of two monocotylids C. kroyeri (Tappenden \& Kern, 1991) and Heterocotyle sp. (Justine \& Mattei, 1983b). In contrast, the posterior spermatozoon extremity of $C$. affinis exhibiting one tapering axoneme (present study), corresponds to this region of the monocotylids, C. australiensis, Monocotyle helicophallus (Watson \& Rohde, 1994), Troglocephalus rhinobatidis, Neoheterocotyle rhinobatidis, Merizocotyle australensis (Watson, 1997), and D. coeliaca (Bruňanská et al., 2017). The above-mentioned dimorphism of the posterior extremity of the spermatozoa of three Calicotyle spp. was reported also in Amphilina spp. (Bruňanská et al., 2012; Rohde \& Watson 1986). The ultrastructure of the posterior extremity of the spermatozoa might be a suitable criterion for taxonomy and/or phylogeny in the Monogenea, as is already the case in the Digenea (Bakhoum et al., 2017). Therefore, it would be desirable to get more detailed information about the spermatozoa of a wider spectrum of species of the monopisthocotylean Monogenea.

Atypical spermatozoa possessing four axonemes were occasionally found in the monocotylids $C$. affinis (present study) and $D$. coeliaca (Bruňanská et al., 2017). In contrast, spermatozoa with three axonemes were detected in C. kroyeri (Tappenden \& Kern, 1991) and H. capricornensis (Watson \& Chisholm, 1998). The latter authors considered these atypical spermatozoa as abnormal/ artefactual. On the other hand, the presence of spermatozoa with three or four axonemes in vas deferens may suggest their potential participation in the process of copulation. A direct and successful participation of these atypical spermatozoa in the process of fertilization is more than questionable.

The present study has demonstrated that the spermatozoa of $C$. affinis resemble those of congeneric $C$. australiensis in particular with the presence of basic ultrastructural characters (the two axonemes of equal length, a complex end-piece, the posterior extremity with one axoneme). These findings support statements concerning close similarity of $C$. affinis Scott, 1911 from Chimaera monstrosa L. in the North Sea to C. australiensis Rohde, Heap, Hayward \& Graham, 1992 from Chimaera sp. II off the eastern coast of Australia (see Chisholm et al., 1997). In addition, the pattern of spermiogenesis in $C$. affinis indicates a basal position of Calicotyle and Dictyocotyle within the Monocotylidae as also indicated by molecular analysis (Chisholm et al., 2001).

\section{Acknowledgements}

The authors would like to specially thank Dr. Willy Hemmingsen, University of Tromsø (Norway), and the staff of the RV 'Johan Ruud', of the University for their help with the fishing and material collection. The authors are grateful to the staff of the Centre of Electron Microscopy, I.D. Papanin Institute for the Biology of Inland Waters, Russian Academy of Sciences, Borok, Russia, for technical assistance. The present study was supported by the Russian Foundation for Fundamental Research (Project no. 15-04-02890a to LGP) and the Grant Agency of the Slovak Republic VEGA (Project no. 2/0104/16 to MB). The work was realized within a frame of Centre of Excellence for Parasitology (Code ITMS: 26220120022) based on the support of the Operational Programme "Research \& Development" funded from the European regional Development Fund (rate 0.4).

\section{References}

Bakhoum, A.J.S., Miquel, J., Ndiaye, P.I., Justine, J.-L., Falchl, A., BÂ, C.T., Marchand, B., QuILICHINI, Y. (2017): Advances in spermatological characters in the Digenea: review and proposal of spermatozoa models and their phylogenetic importance. Adv. Parasitol., 98: in press.

BRUŇANSKÁ, M. (2010): Recent insights into spermatozoa development and ultrastructure in the Eucestoda. In: Lejeune, T., Delvaux, P. (Eds) Human spermatozoa: maturation, capacitation and abnormalities. Nova Science Publishers, Inc., New York, pp. 327 - 354 Bruñanská, M., Bílý, T., NebesÁŘovÁ, J. (2015): Nippotaenia mogurndae Yamaguti et Myiata, 1940 (Cestoda, Nippotaeniidea): first data on spermiogenesis and sperm ultrastructure. Parasitol. Res., 114: 1443 - 1453. DOI: 10.1007/s00436-015-4327-0

Bruñanská, M., Mackiewicz, J.S., Poddubnaya, L.G. (2017): Spermatological characteristics of the enigmatic monogenean Dictyocotyle coeliaca Nybelin, 1941 (Monopisthocotylea: Monocotylidae) reveal possible adaptation to endoparasitism. Acta Parasitol., 62: 110 - 120. DOI: 10.1515/ap-2017-0013

Bruñanská, M., Poddubnaya, L.G., Xylander, W.E.R. (2012): Spermatozoon cytoarchitecture of Amphilina foliacea (Platyhelminthes, Amphilinidea). Parasitol. Res., 111: 2063 - 2069. DOI: 10.1007/ s00436-012-3053-0

Chisholm, L.A., Wheeler, T.A., Beverley-Burton, M. (1995): A phylogenetic analysis and revised classification of the Monocotylidae Taschenberg, 1879 (Monogenea). Syst. Parasitol., 32: 159 - 191. DOI: 10.1007/BF00008827

Chisholm, L.A., Hansknecht, T.J., Whittington, I.D., Overstreet, R.M. (1997): A revision of the Calicotylinae Monticelli, 1903 (Monogenea: Monocotylidae). Syst. Parasitol., 38: 159 -183. DOI: 10.1023/A:1005844306178

Chisholm, L.A., Morgan, J.A.T., Adlard, R.D., Whittington, I.D. (2001): Phylogenetic analysis of the Monocotylidae (Monogenea) 
inferred from 28S rDNA sequences. Int. J. Parasitol., 31: 1537 1547. DOI: 10.1016/S0020-7519(01)00313-7

EHLERS, U. (1985): Phylogenetic relationship within the Platyhelminthes. In: Conway Morris, S., George, J.D., Gibson, R., Platt, H.M. (Eds) The origin and relationships of lower invertebrates. Oxford University Press, Oxford, pp. 143 - 158

Hoberg, E.P., Mariaux, J., Brooks, D.R. (2001): Phylogeny among the orders of the Eucestoda (Cercomeromorphae): integrating morphology, molecules and total evidence. In: Littlewood, D.T.J., Bray, R.A. (Eds) Interrelationships of the Platyhelminthes. Taylor and Francis, London, New York, pp. 112 - 126

Justine, J.L. (1991a): Cladistic study in the Monogenea (Platyhelminthes), based upon a parsimony analysis of spermiogenetic and spermatozoal ultrastructural characters. Int. J. Parasitol., 21: 821 $-838$

Justine, J.L. (1991b): Phylogeny of parasitic Platyhelminthes: a critical study of synapomorphies proposed on the basis of the ultrastructure of spermiogenesis and spermatozoa. Can. J. Zool., 69: $1421-1440$

Justine, J.L. (1993): Phylogénie des Monogènes basée sur une analyse de parcimonie des caractères de l'ultrastructure de la spermiogenèse et des spermatozoïdes incluant les résultats récents. [Phylogeny of the Monogenea based upon a parsimony analysis of characters of spermiogenesis and spermatozoon ultrastructure including recent results]. Bull. Fr. Pêche Pisci, 328: 137 - 155 (In French)

JustinE, J.L. (1998): Spermatozoa as phylogenetic characters for the Eucestoda. J. Parasitol., 84: 385 - 408

JUSTINE, J.L. (2001): Spermatozoa as phylogenetic characters for the Platyhelminthes. In: Littlewood, D.T.J., Bray, R.A. (Eds) Interrelationships of the Platyhelminthes. Taylor and Francis, London, pp. $231-238$

JustinE, J.L., MAtTEI, X. (1983a): Etude ultrastructurale comparée de la spermiogenèse des Monogènes. I. Megalocotyle (Monopisthocotylea, Capsalidae). [Comparative ultrastructural study of spermiogenesis in Monogeneans (Flatworms). I. Megalocotyle (Monopisthocotylea, Capsalidae)]. J. Ultrastr. Res., 82: 296 - 308 (In French)

Justine, J.L., Mattel, X. (1983b): Comparative ultrastructural study of spermiogenesis in Monogeneans (Flatworms). 2. Heterocotyle (Monopisthocotylea: Monocotylidae).J. Ultrastr. Res., 84: 213-223 Justine, J.L., Mattel, X. (1983c): Comparative ultrastructural study of spermiogenesis in Monogeneans (Flatworms). 3. Two species of Amphibdelloides (Monopisthocotylea Amphibdellatidae). J. Ultrastr. Res., 84: $224-237$

Justine, J.L., MATtel, X. (1984): Comparative ultrastructural study of spermiogenesis in monogeneans (Flatworms). 3. Diplectanum
(Monopisthocotylea: Diplectanidae). J. Ultrastr. Res., 88: 77 - 91 Justine, J.L., MAtTEI, X. (1986): Comparative ultrastructural study of spermiogenesis in monogeneans (Flatworms). 5. Calceostoma (Monopisthocotylea: Calceostomatidae). J. Ultrastr. Mol. Str. Res., $96: 54-63$

Justine, J.L., Mattel, X. (1987): Phylogenetic relationships between the families Capsalidae and Dionchidae (Platyhelminthes, Monogenea, Monopisthocotylea) indicated by the comparative ultrastructural study of spermiogenesis. Zool. Scr., 16: 111 - 116 Justine, J.L., Lambert, A., Mattel, X. (1985): Spermatozoon ultrastructure and phylogenetic relationships in the Monogenea (Platyhelminthes). Int. J. Parasitol. 15: 601 - 608

KeARn, G., Whittington, I. (2015): Sperm transfer in monogenean (platyhelminth) parasites. Acta Parasitol., 60: 567 - 599. DOI: 10.1515/ap-2015-0082

Levron, C., Miquel, J., Oros, M., Scholz, T. (2010): Spermatozoa of tapeworms (Platyhelminthes, Eucestoda): advances in ultrastructural and phylogenetic studies. Biol. Rev., 85: 523 - 543. DOI: 10.1111/j.1469-185X.2009.00114.x

ROHDE, K. (1988): Phylogenetic relationship of free-living and parasitic Platyhelminthes on the basis of ultrastructural evidence. In: Ax, P., Ehlers, U. (Eds) Free-living and symbiotic Platyhelminthes. Gustav Fischer Verlag, Stuttgart, New York, pp. 353 - 357

ROHDE, K., WATSON, N. (1986): Ultrastructure of spermatogenesis and sperm of Austramphilina elongata (Platyhelminthes, Amphilinidea). J. Submicrosc. Cytol., 18: $361-374$

Sproston, N.G. (1946): A synopsis of the monogenetic trematodes. Trans. Zool. Soc. London, 25: 185 - 600

TAPPEnden, T., KeARN, G.C. (1991): Spermiogenesis and sperm ultrastructure in the monocotylid monogenean Calicotyle kroyeri. Int. J. Parasitol., 21: 57 - 63. DOI:10.1016/0020-7519(91)90120-V WATSON, N.A. (1997): Spermiogenesis and sperm ultrastructure in Troglocephalus rhinobatidis, Neoheterocotyle rhinobatidis and Merizocotyle australensis (Platyhelminthes, Monogenea, Monopisthocotylea, Monocotylidae). Int. J. Parasitol., 27: 389 - 401. DOI: 10.1016/S0020-7519(96)00203-2

Watson, N.A., ChISholm, L.A. (1998): Spermatozoa and spermiogenesis in the monocotylid Heterocotyle capricornensis (Platyhelminthes, Monogenea, Monopisthocotylea), including observations of aberrant folding and fusing of spermatozoa in one individual. Folia Parasitol., 45: $211-220$

WATSON, N.A., ROHDE, K. (1994): Ultrastructure of sperm and spermiogenesis in the monocotylid monogeneans Monocotyle helicophallus and Calicotyle australiensis (Platyhelminthes). Int. J. Parasitol., 24: 1019 - 1030. DOI:10.1016/0020-7519(94)90168-6 Yamaguti, S. (1963): Systema helminthum. Monogenea and Aspidocotylea, vol IV. Interscience Publishers, New York, 699 pp. 